\title{
Palliative care needs among patients with advanced illnesses in Bhutan
}

\author{
Tara Devi Laabar ${ }^{1,2^{*}}$ (D) Christobel Saunders ${ }^{3}$, Kirsten Auret ${ }^{4}$ and Claire E. Johnson ${ }^{1,5,6}$
}

\begin{abstract}
Background: Palliative care improves the quality of lives of patients and families affected by advanced illnesses through the prevention and relief of suffering. While palliative care is well established in developed countries, it is inadequate or non-existent in most developing countries. Palliative care is an emerging concept in Bhutan, a tiny Himalayan Kingdom. A small community palliative care service is available in the national referral hospital with three dedicated inpatient palliative care beds. This study explored the needs for palliative care among patients diagnosed with advanced illnesses and is a component of a larger project aimed to inform a suitable palliative care model for the country.
\end{abstract}

Methods: This is a cross-sectional descriptive study. A survey, using a structured questionnaire including the EORTC QLQ-C30, was carried out among patients with advanced illness in hospitals, primary care units and communities across the country. Purposeful and snowball sampling strategies were used to recruit study participants.

Results: Seventy (76\%), out of 93 eligible patients, agreed to participate in the survey. Participants reported low to moderate scores on physical, role, emotional, cognitive and social functioning, a moderate score for the global health/ quality of life scale and moderately high (worse) scores in symptoms including fatigue, pain, insomnia, loss of appetite and the financial impact from the disease.

Conclusions: The symptom burden experienced by patients affected by advanced illnesses demonstrates the need for palliative care in Bhutan. These findings will help inform the development of a public health-focused palliative care model, modified to the Bhutanese context, as recommended by the World Health Organization.

Keywords: Bhutan, Palliative care, Advanced illnesses, Public health strategy, Symptoms, Function, cancer, Nonmalignant

\section{Background}

Advanced illnesses such as cancer and other nonmalignant conditions can cause overwhelming suffering in patients and families demanding not only medical expertise but also support for the psychological, social, emotional, and spiritual distress throughout the disease trajectory [1]. Palliative care (PC), identified as a

\footnotetext{
* Correspondence: taradevilaabar@research.uwa.eduau

'Medical School, The University of Western Australia, 35 Stirling Highway, 6009 Perth, Western Australia, Australia

${ }^{2}$ Department of Nursing, Faculty of Nursing and Public Health, Khesar Gyalpo University of Medical Sciences of Bhutan, Thimphu, Bhutan

Full list of author information is available at the end of the article
}

fundamental human right [2-4], is an approach to care that improves the quality of life of patients and families through the prevention and relief of suffering [5]. Provided across health care settings, PC is patient- and family-focussed, based on ethical principles, shared decision making, advanced care planning and excellent symptom management [6]. As a multidisciplinary approach, PC can be initiated at the diagnosis of a lifethreatening disease along with the therapeutic management, continued throughout the disease trajectory until end-of-life and extended to grief and bereavement support of family members [7].

(c) The Author(s). 2021 Open Access This article is licensed under a Creative Commons Attribution 4.0 International License, which permits use, sharing, adaptation, distribution and reproduction in any medium or format, as long as you give appropriate credit to the original author(s) and the source, provide a link to the Creative Commons licence, and indicate if changes were made. The images or other third party material in this article are included in the article's Creative Commons licence, unless indicated otherwise in a credit line to the material. If material is not included in the article's Creative Commons licence and your intended use is not permitted by statutory regulation or exceeds the permitted use, you will need to obtain permission directly from the copyright holder. To view a copy of this licence, visit http://creativecommons.org/licenses/by/4.0/. The Creative Commons Public Domain Dedication waiver (http://creativecommons.org/publicdomain/zero/1.0/) applies to the data made available in this article, unless otherwise stated in a credit line to the data. 
In response to continuous efforts by the World Health Organization (WHO) and other international organizations to ensure universal access $[8,9]$, PC services are mostly well established in developed countries $[1,10]$. However, out of 56 million annual global deaths, almost 40 million happen in developing countries [11], and more than 33 million of those could benefit from PC [12]. In 2014, it was estimated that $78 \%$ of adults and $98 \%$ of children requiring $\mathrm{PC}$ were in low and middleincome-countries (LMIC) [1]. It is predicted that by 2060, 48 million people will die annually while experiencing serious health-related suffering and $83 \%$ of these deaths will occur in LMICs [13]. In 2014, the World Health Assembly declared that PC is an ethical responsibility of health systems and an ethical duty of all health care providers [14]. Tragically, PC still remains very minimal or non-existent in most developing countries $[1,10,15-17]$. The WHO, having identified several barriers in the provision of $\mathrm{PC}$ in developing countries, recognised PC as a public health priority and recommended four key strategies; (1) appropriate policies, (2) adequate availability of medications (including opioids), (3) education of health care workers and the public, and (4) implementation of PC services at all levels of health care $[18,19]$.

Bhutan, a tiny Himalayan Kingdom, a size similar to that of Switzerland, with a population of 771,608 [20], is landlocked between two giant nations of the world, China and India. Popularly known to the world for its concept of Gross National Happiness, Bhutan has made steady progress in modernization and poverty reduction since the early 1960s. Its annual per capita income stands at US\$ 3438.16 [20], and the United Nations has recommended its eligibility to graduate to a middle income country by 2021 [21].

Healthcare in Bhutan is provided through a threetiered system where the Basic Health Unit (BHU) functions at the primary level, district hospitals at the secondary level and the regional and national referral hospitals at the tertiary level. The integration of traditional medicine with the national health system is unique to Bhutan [22]. Having advanced both economically and socially, the disease patterns have altered significantly over the years. While vaccine-preventable diseases like polio are almost eradicated, infectious diseases such as HIV, dengue fever and Multi-Drug Resistant Tuberculosis (MDR-TB) are still on the rise [23]. Life expectancy has doubled from 35 in the 1960s to 70 in 2015 [24] and the incidence of non-communicable diseases like heart, lung, liver and kidney diseases and cancer are increasing [25]. Cancer is often diagnosed at an advanced stage in Bhutan [26].

Despite the growing number of people dying with conditions that are likely to benefit from $\mathrm{PC}$, its development remains at a nascent stage in Bhutan. In 2018, a home-based PC group, consisting of a few nurses and doctors who received PC training in India, was initiated at the Jigme Dorji Wangchuck National Referral Hospital (JDWNRH) primarily for pain management for cancer patients. In addition, three beds were allocated for PC in the oncology ward in JDWNRH [26]. However, the needs for PC among patients with advanced illnesses have not been studied. This paper is a component of a larger study aimed to inform the development of a suitable PC model, socially, culturally and spiritually applicable, for Bhutan. The objective of this paper is to explore PC needs among patients with advanced illness.

\section{Methods}

\section{Study design and setting}

This study is a cross-sectional descriptive study using structured patient interviews. Data collection was scheduled for May to July 2019 in an attempt to avoid the usual monsoon season in Bhutan, which routinely disrupts travelling through the mountainous areas. Study sites included the JDWNRH, two regional referral hospitals, district hospitals and Basic Health Units (BHUs), both Grade I and Grade II, spread across Bhutan as indicated in Fig. 1. Basic Health Unit Grade I is a 10-bed community hospital equipped with basic diagnostic facilities managed by one or two general doctors along with a few nurses and allied health workers. Basic Health Unit Grade II is a primary health care centre managed by health assistants.

\section{Study population and sampling}

Patients with advanced illness, defined in this study as having little chance of cure (e.g. cancer, heart, lung, kidney, liver failure, motor neuron disease, Parkinson's disease, Huntington's disease, Alzheimer's disease/ dementia, and HIV/ AIDS), and those at the end-of-life, in their last weeks/days of life - literally dying irrespective of the diagnosis, were included. The doctors, nurses and allied health care workers (particularly physiotherapists) helped in identifying the patients. We also recruited a gangrenous perineal wound which was likely to be ultimately incurable. Purposeful sampling, guided by diagnosis, end-of-life status, and willingness to participate, was used to recruit patients in the hospital. In the communities, using a snowball sampling strategy, patients nominated by clinicians were approached at their homes. Participants were excluded if they were $<18$ years, diagnosed with acute illness, unconscious, semiconscious or delirious who could not give consent and those who were unwilling to participate. The final study size was determined pragmatically, in consideration of the eligible/willing participants and the duration of field work. 


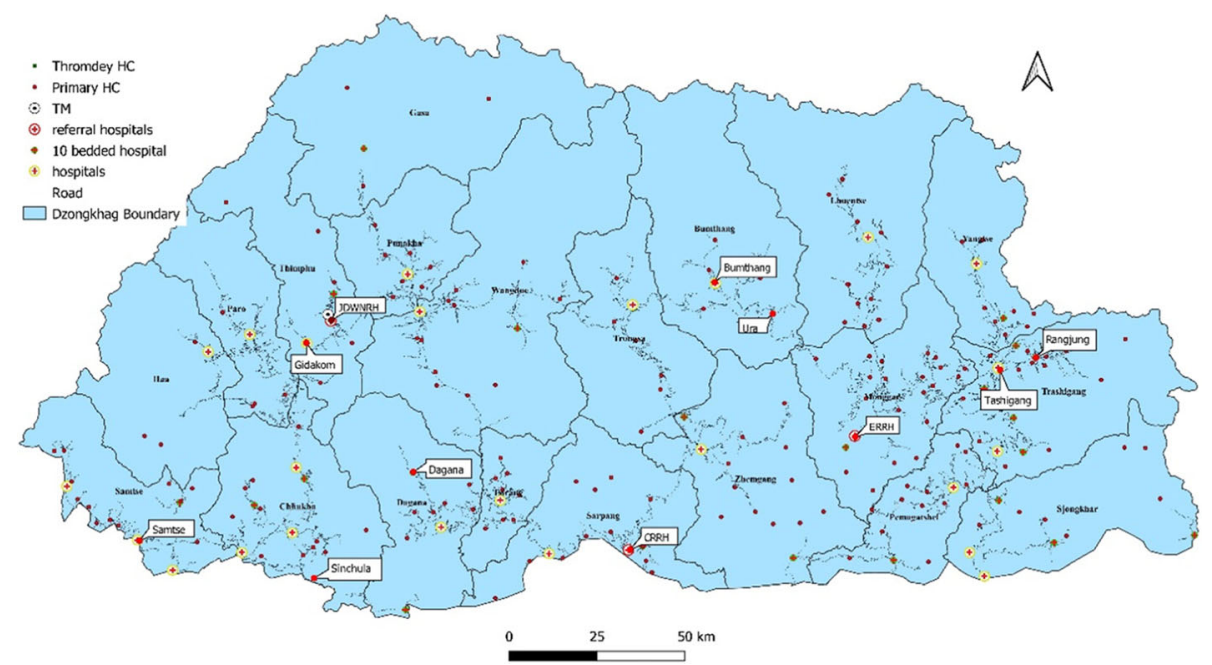

Fig. 1 Map of Bhutan showing the study sites marked within the boxes. (Used with permission from the Policy \& Planning Division, Ministry of Health, Bhutan

\section{Survey instrument}

Data were collected using structured interviews to complete a questionnaire which included questions about socio-demographic characteristics, the clinical information of the patients and the European Organisation for Research and Treatment of Cancer (EORTC) quality of life questionnaire (EORTC QLQ-C30), see supplementary file. The latter is an integrated, 30-item questionnaire, to assess the health related quality of life (QOL) of cancer patients participating in both clinical trials as well as non-trial studies for which reliability and validity have already been established [27].

The EORTC QLQ-C30, used to determine the physical, psychological, social functioning and overall quality of life of patients, includes five functional scales (physical, role, emotional, cognitive, and social functions), three symptom scales (fatigue, nausea and vomiting, and pain), and a two-item global health and quality-of-life scale. The remaining six single items assess additional symptoms including dyspnoea, appetite loss, sleep disturbance, constipation, and diarrhoea, as well as the perceived financial impact of the disease and treatment. For the functional scales and global health status/QOL, the scores range from 0 to 100 , with a higher score representing a higher level of functioning and QOL. The symptom scale scores also range from 0 to 100 , however, higher scores represents a greater degree of symptoms or problems.

Although the EORTC QLQ-30 was specifically developed for cancer patients [27, 28], past studies [29] have used it to compare the QOL between cancer and noncancer patients. Given the complexities of low literacy levels and prevalence of non-written dialects and, moreover, not every patient could read, write or speak the national language, translating the EORTC QLQ-C30 to Dzongkha, the national language, was not feasible. Thus, the EORTC QLQ-C30, English version, was considered to be the most appropriate tool for the study. The required consent to use this tool was obtained from the EORTC. A pilot test, conducted with four patients at JDWNRH, the two regional referral hospitals and Trashigang district hospital, found that the survey did not require changes as there were no issues regarding clarity and sensitivity of the questions.

\section{Data collection}

Field notes were maintained to record any difficulties during data collection to allow TDL reflective consideration or potential bias during interpretation. To ensure that all potential participants were supported to be involved, generous time was set aside so that each patient was comfortable. Patients who could read and write English completed the survey questionnaire by themselves, if they wished. For the majority who could not read and write, TDL, who is fluent in all the main dialects used in Bhutan, was available to translate all information and the questionnaire at the bedside and completed the questionnaire in English on the participants' behalf.

\section{Data analyses}

Statistical analyses were conducted using the Statistical Analysis System (SAS) software, version 9.4 [30]. Firstly, descriptive statistics were calculated; means and standard deviation (SD) for interval data, and frequency and percentage for categorical data. There was no missing data. An independent sample T-test was conducted to compare the EORTC QLQ-30 scores between cancer and non-cancer patients. Statistical significance level was 
set at alpha 0.05. The graphical illustrations were generated using Microsoft Excel, version 16.0.

\section{Ethical consideration}

Ethical approval was provided by the Human Research Ethics Committee at the University of Western Australia and the Research Ethics Board of Health in Bhutan with Reference numbers, RA/4/20/4990 and REBH/Approval/ 2018/097, respectively. While the overall administrative clearance for the study was provided by the Policy and Planning Division in the Ministry of Health in Bhutan, permission to access the patients was obtained from the administration of the individual study site. Informed consent was taken from every participant in the form of signature or thumb print.

\section{Results}

\section{Field notes}

Data collection was hampered by several unforeseen difficulties including a severe cyclone [31] which made travelling from one study site to another impossible, and a tragic accident [32] involving a public bus hit by a landslide, resulted in a government caution against public travel. Recruitment was slower than expected because a large number of potential participants were too ill, in pain or in distress to be approached. Most of the patients were illiterate, however, even many of those who could read and write preferred the researcher to read and explain the participant information form and felt most comfortable to fill the questionnaire along with the researcher. Only nine patients filled the questionnaire independently. None of the patients became distressed requiring assistance while completing the survey.

\section{Participants}

Out of 93 eligible patients identified, 70 (76\%) agreed to participate. Ten (14\%) patients were recruited from the community and the remainder $(60,86 \%)$ from hospitals. Among the 23 patients who did not participate, 9 (39\%) were too ill or in too much pain and distress and 8 (35\%) were not able to provide consent due to being unconscious, semi-conscious, delirious or with hearing and speaking disability. Four (17\%) patients were not allowed to participate by their family members who feared that their loved ones would be aware of the serious prognosis of the illness. The remaining 2 (9\%) who declined to participate did not provide a specific reason. Eighty seven percent of the patients had to be guided through the questionnaire.

\section{Sociodemographic characteristics}

Participating patients' ages ranged from 18 to 85 years (mean 46.1, SD 15.5). The majority were married (53, $76 \%$ ) and had at least 1 child (57, 81\%). Among those who had more than 1 child, the eldest child's age ranged from 6 to 69 years, (mean 25.6, SD 13.2) and the youngest child's age from 1 to 47 years, (mean 16.8, SD 10.3). The sociodemographic characteristics are presented in Table 1.

\section{Clinical information of the patients}

Sixty two (89\%) patients knew their diagnosis and the remaining eight (11\%) wished to know. A large minority of the patients $(n=29,42 \%)$ were diagnosed with advanced cancer and the rest had a range of advanced non-malignant conditions (Fig. 2). The majority of the patients, $(n=46,66 \%)$ reported that they were admitted to the hospital for 1 to 3 times, $16 \%$ for 4 to 6 times, and $10 \%$ for more than 7 times since diagnosis. For 41 (59\%) patients, the longest admission to hospital lasted more than 2 weeks.

\section{Descriptive statistics for patients using EORTC-QLQ-30}

The functional scales demonstrated low to moderate levels of functioning, with scores ranging from 32.1 for Role to 57.6 for the Cognitive Scale. The symptom scales including the single item symptoms ranged from low (good) with diarrhoea (20.0) through to moderate problems (fatigue 61.6) and a severe (worse) problems related to the financial impact of the illness (74.3). The mean score for the global health/QOL scale was 47.4. There were no differences in EORTC symptom or functioning subscales between cancer and non-cancer patients $(p=$ $<0.05)$ except for constipation $(p<0.001)$. The results of the EORTC subscales are shown in Table 2.

\section{Discussion}

A better understanding of the factors influencing the QOL among patients with advanced illness can facilitate policy development, particularly in resource constrained countries [33]. Herrera and colleagues [34] remind us that PC provision should not be determined by the patient's geographical location, his/ her disease, or ability to pay, but on needs alone. Other studies [35, 36] further support the contention that needs assessed deliberately among patients provides useful information to plan programmes and interventions that meet the explicit requirements of a local population. The findings of this study, although a relatively small sample, when combined with the findings from the other concurrent studies among family members and health care professionals, are fundamental to informing the development of PC services in Bhutan.

Forty two percent of the patients in the study had advanced cancer. Cancer in Bhutan has increased from 923 new cases in 2013 to 1,824 in 2017. Cancer is identified as a major threat to public health in the developing 
Table 1 Sociodemographic characteristics of patients

\begin{tabular}{|c|c|c|}
\hline & \multicolumn{2}{|c|}{ Patients $(n=70)$} \\
\hline & $n$ & $\%$ \\
\hline \multicolumn{3}{|l|}{ Gender } \\
\hline Female & 39 & 55.7 \\
\hline Male & 31 & 44.3 \\
\hline \multicolumn{3}{|l|}{ Marital status } \\
\hline Married & 53 & 75.7 \\
\hline Never married & 9 & 12.9 \\
\hline Widowed & 4 & 5.7 \\
\hline Divorced & 3 & 4.3 \\
\hline Separated & 1 & 1.4 \\
\hline \multicolumn{3}{|l|}{ Have Children } \\
\hline Yes & 57 & 81.4 \\
\hline No & 13 & 18.6 \\
\hline \multicolumn{3}{|c|}{ How many children $(n=57)$} \\
\hline $1-3$ & 39 & 68.4 \\
\hline $4-6$ & 16 & 28.1 \\
\hline $7-9$ & 2 & 3.5 \\
\hline \multicolumn{3}{|l|}{ Spoken language } \\
\hline Sharchopkha & 28 & 40.0 \\
\hline Dzongkha & 24 & 34.3 \\
\hline Lhotshamkha & 12 & 17.1 \\
\hline Others $^{\mathrm{a}}$ & 6 & 8.6 \\
\hline \multicolumn{3}{|l|}{ Education level } \\
\hline Never been to school & 29 & 41.4 \\
\hline Higher secondary & 10 & 14.3 \\
\hline Primary & 9 & 12.9 \\
\hline Bachelors \& above & 8 & 11.4 \\
\hline Middle Secondary & 6 & 8.6 \\
\hline Monastic/religious & 5 & 7.1 \\
\hline Non-formal education & 3 & 4.3 \\
\hline \multicolumn{3}{|l|}{ Occupation } \\
\hline Housewife & 24 & 34.3 \\
\hline Private/Corporate & 15 & 21.4 \\
\hline Civil servant & 8 & 11.4 \\
\hline Self-employed & 4 & 5.7 \\
\hline Farmer & 3 & 4.3 \\
\hline Others $^{b}$ & 16 & 22.9 \\
\hline
\end{tabular}

${ }^{\mathrm{a} B u m t h a p k h a, ~ K h e n g k h a, ~ K u r t o e p k h a ; ~}{ }^{\mathrm{b}}$ Monk, nun, student, retired army, retired civil servant, not employed, security guard, NGO employee

countries [37]. The remaining 58\% were diagnosed with advanced, non-malignant diseases including both communicable and chronic diseases. In 2017, along with 144 cancer deaths, 212 deaths related to heart disease, 166 to alcoholic liver disease and 39 to chronic kidney disease were reported [25]. Substantial numbers of chronic patients also die at home without a cause of death being reported.

When diagnosed with cancer, both the patient and family experience a wide range of needs throughout the illness trajectory, ranging from physical needs to emotional, psychological, social, financial and spiritual needs [38]. The needs of patients with non-malignant conditions are now increasingly identified [39-41]. This research found that people diagnosed with advanced malignant and non-malignant illnesses in Bhutan have poor levels of functioning and varied levels of symptom severity indicating high support needs, consistent with advanced illnesses in other LMICs [33, 42-45]. There was no differences in symptom severity or level of functioning between cancer and non-cancer patients except for constipation ( $p$ value $<0.05$ ). This is in contrast to a study of elderly cancer patients in Sweden who had poorer scores, more complaints and subsequently poorer quality of life compared to non-cancer patients [29].

There are no published studies of normative EORTC QLQ-C30 data among Asian PC populations. The existing normative data is most available for general populations and the mean scores for the Global Health/QOL across Australia (68.5, SD 21.5), Columbia, (77.1, SD 18.5), the European countries (66.1, SD 21.7) and Korea (67.7, SD 68.8) provide a picture of quality of life scores for those without advanced illness [46-49]. One study from Ethiopia [33] which focused on people mostly diagnosed with later stage cancer, reported a better mean global health/QOL score than patients with advanced illnesses in Bhutan (Ethiopia 54.6, SD 26.2 compared with Bhutan 47.4, SD 24.1) despite the mean score for pain in cancer patients in the two countries being similar (Ethiopia 55, SD 36.2, Bhutan 55.2, SD 35.7). Symptoms like fatigue and financial difficulties related to the illness are worse among Bhutanese cancer patients (59.4, SD 34.8 and 81.6 , SD 36.3, respectively) compared to Ethiopian cancer patients (52.6, SD 36.1, and 67.1, SD 41.2, respectively) and much more than the general population in the aforementioned countries [33, 46-49]. These comparisons highlight the need for a model of PC in Bhutan which considers the social and economic context of patients in addition to their disease and symptom management priorities.

In this study, both cancer and non-cancer patients experienced moderate pain (mean 46.2, SD 37.1). Pain is one of the most common and feared symptoms experienced by patients with advanced illnesses [6], and can significantly influence the psychological and emotional wellbeing and overall QOL of both patients and families $[50,51]$. In Bhutan, although oral morphine is available at all levels of healthcare except in BHU Grade II [52], it may be inadequately used as $\mathrm{PC}$ is an emerging concept [26]. Where PC is not well developed, several barriers to 


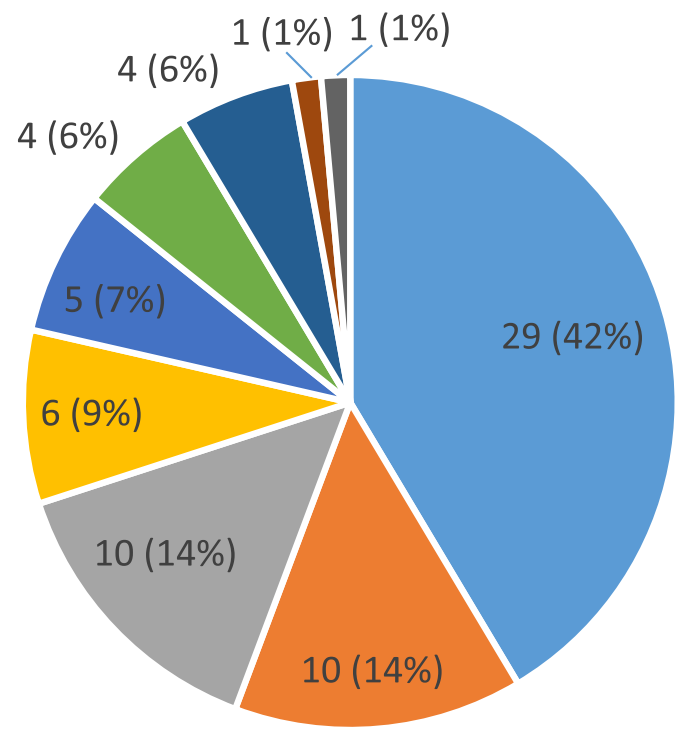

- Cancer

- Chronic Kidney Disease

- Multidrug resistant TB

- HIV

- Alcoholic liver disease

- Spinal Cord Injury

- Chronic lung disease

- Systemic lupus

erythematosus

Fig. 2 Diagnosis of the patients $(n=70)$

accessing morphine have been reported, including lack of availability, limited knowledge and opiophobia among physicians, along with a reluctance by patients and families to use it $[53,54]$. The need to improve pain management is a priority area for new PC services in Bhutan.
Social problems were far reaching for participants, in addition to their medical condition. Most were married and many had young children. In one case the eldest child was just six years old and in another the youngest was just one. Parenthood is one of the major concerns

Table 2 The EORTC QLQ-C30 mean scores and comparison between cancer and non-cancer patients

\begin{tabular}{|c|c|c|c|c|c|c|c|c|}
\hline \multirow[t]{3}{*}{ 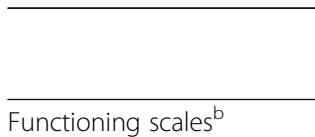 } & \multirow[t]{2}{*}{ Item $^{a}$} & \multicolumn{2}{|c|}{ Cancer patients } & \multicolumn{2}{|c|}{ Non-cancer patients } & \multicolumn{2}{|c|}{ Combined patients } & \multirow{2}{*}{$\begin{array}{l}p \text {-Value } \\
(<0.05)\end{array}$} \\
\hline & & Mean Score & (SD) & Mean Score & (SD) & Mean Score & (SD) & \\
\hline & \multicolumn{8}{|c|}{ Functioning scales ${ }^{\mathrm{b}}$} \\
\hline Physical & $15-19$ & 39.1 & $(31.4)$ & 43.6 & $(34.6)$ & 41.7 & (33.1) & 0.573 \\
\hline Role & 20,21 & 31.6 & (39.9) & 32.5 & (39.4) & 32.1 & (39.4) & 0.925 \\
\hline Emotional & $35-38$ & 39.9 & $(38.0)$ & 39.2 & $(37.6)$ & 39.5 & $(37.5)$ & 0.938 \\
\hline Cognitive & 34,39 & 58.6 & $(27.7)$ & 56.9 & $(27.4)$ & 57.6 & (27.3) & 0.799 \\
\hline Social & 40,41 & 43.7 & $(38.7)$ & 33.7 & $(36.6)$ & 37.9 & $(37.5)$ & 0.283 \\
\hline Global health/ QOL scale & 43,44 & 48.6 & $(21.4)$ & 46.5 & $(26.2)$ & 47.4 & $(24.1)$ & 0.724 \\
\hline \multicolumn{9}{|c|}{ Symptom scales and/or items ${ }^{c}$} \\
\hline Fatigue & $24,26,32$ & 59.4 & $(34.8)$ & 63.1 & $(29.8)$ & 61.6 & $(31.7)$ & 0.639 \\
\hline Nausea and vomiting & 28,29 & 19.5 & $(30.6)$ & 26.8 & $(33.5)$ & 23.8 & (32.3) & 0.349 \\
\hline Pain & 23,33 & 55.2 & $(35.7)$ & 39.8 & $(37.2)$ & 46.2 & (37.1) & 0.087 \\
\hline Dyspnoea & 22 & 25.3 & $(34.1)$ & 34.1 & $(37.6)$ & 30.5 & $(36.2)$ & 0.309 \\
\hline Insomnia & 25 & 43.7 & $(39.9)$ & 36.6 & $(37.1)$ & 39.5 & $(38.2)$ & 0.454 \\
\hline Appetite loss & 27 & 41.4 & $(38.5)$ & 43.9 & (35.3) & 42.9 & (36.4) & 0.781 \\
\hline Constipation & 30 & 50.6 & $(34.1)$ & 17.1 & $(27.0)$ & 31.0 & $(34.2)$ & $<0.001$ \\
\hline Diarrhoea & 31 & 20.7 & $(28.7)$ & 19.5 & $(29.8)$ & 20.0 & $(29.2)$ & 0.868 \\
\hline Financial impact & 42 & 81.6 & $(36.3)$ & 69.1 & $(40.4)$ & 74.3 & $(39.0)$ & 0.180 \\
\hline
\end{tabular}

${ }^{a}$ Numbers as per the item numbers in the questionnaire; ${ }^{b}$ Functional scale scores range from 0 to 100 , with a higher score representing a higher level of functioning or QOL; ' Symptom scale scores range from 0 to 100 , with higher score representing a greater degree of symptom severity 
when diagnosed with an advanced illness [55], however, the needs specific to dying patients and their dependent children are not well met even in the developed countries with comprehensive PC [56-58].

Forty one percent of participants in this study did not go to school and $13 \%$ had just primary education- indicating that $54 \%$ of the patients had significant problems with literacy. Literacy is an important concern in LMICs given its association with a range of adverse health outcomes [59]. Misinformation and misunderstandings related to PC and hospice services among indigenous populations [60] have emphasized public education as an integral component of $\mathrm{PC}$ which provides information, knowledge and skills enabling patients, particularly the marginalized and vulnerable groups, to adapt effectively when faced with the diagnosis of advanced illness [61]. Given the low levels of literacy in Bhutan and a lack of knowledge about PC, even amongst health professionals, education and raising awareness about PC is important for the public in Bhutan. Integrating PC modules in nursing colleges, postgraduate medicine, regular training programs for in-service health professionals combined with PC awareness initiatives for relevant stakeholders including policy makers are some of the important avenues to develop PC education. Use of national television, radio and other social media platforms can be good strategies to create awareness about PC in Bhutan.

Sixty one percent of the patients in this study did not have a reliable job or income, which was reflected in the high levels of financial stress for both cancer and noncancer patients. Although healthcare in Bhutan, including referral abroad, is funded by the government [62], patients still need to pay for accommodation in private cabins instead of the general hospital ward which is noisy and privacy often compromised; for some medicines that are not included in the essential drug list; and for the services availed from the private diagnostic facilities both within and outside the country [22]. Patients incur expenditure on the repeated travel to and from the referral centres for the treatment and management of their illness. This situation is similar in other countries in the region where rural patients have to travel long distances for treatment and where illness and the time required for treatment further reduces incomes [63, 64]. Moreover, Bhutanese often spend huge amounts of money on rituals, prayers, offerings and other traditional healing practices when confronted with advanced illness because patients and family members strongly believe that diseases are caused by bad, vengeful spirits causing imbalances in the vital elements - bile, phlegm and wind channels, within the body $[65,66]$. Traditional healing practices along with modern medicine are considered to provide parallel benefits in cancer management and end- of-life care, especially in developing countries [60, 6769]. Having traditional medicine integrated into the national health system coupled with well informed and engaged local traditional healers can play a significant role in advancing PC in Bhutan.

Consistent with previous research in both developed and developing countries [28, 42-45, 70, 71], both cancer and non-cancer patients in Bhutan have varied needs throughout their illness that affects their overall QOLranging from physical symptom control to psychological, emotional, cognitive and spiritual support, as well as the need for food and financial assistance. Patients also had information needs about diagnosis, treatment options and side effects along with the need for psychological and spiritual support [35, 72].

Palliative care aims to address the broad range of symptoms and needs of patients with advanced illnesses described in our study. When assessing PC needs for a country or a region, it is vital to understand the benefit of such programmes to the local population [73]. The WHO recommends that a PC service should, at a minimum, identify both cancer and non-cancer patients who could benefit from PC; assess, reassess and address their physical, psychological, social, emotional and spiritual distress and determine culturally appropriate goals of care [6]. In rural Africa, PC integrated into diseasemodifying therapies and into the routine HIV services have reduced physical pain and improved psychosocial and spiritual wellbeing including socioeconomic assistance for most patients [74, 75]. Concurrent PC among advanced cancer patients is perceived by oncologists to improve the quality of life of patients and families, facilitate better quality of care with less aggressive end-of-life care, and reduce emotional distress [76]. Given that PC is a young concept in Bhutan, these findings are relevant and applicable to the Bhutanese context as education and awareness programs are crucial to introducing PC services.

Patients with advanced illnesses in this study were admitted to the hospital many times since diagnosis, and the majority (59\%) spent at least 2 weeks in hospital during each admission. Several studies [10, 18, 77, 78] have found that effective PC services can avoid repeated, often unnecessary, visits to emergency departments at the end-of-life. Palliative care services have also reduced long-term hospital admissions and the referral of patients abroad, thus reducing health care costs. Almost $40 \%$ of the health care expenses are known to occur in the last 3 months of life and account for almost $70 \%$ of end-of-life expenditures [79]. The government of Bhutan is challenged by the escalating cost of health care [22]. Integrating a public health approach to $\mathrm{PC}$ into the existing health care system can help manage the increasing costs. 
While the principles of $\mathrm{PC}$ remain universal, the WHO and other international organizations reiterate that PC models should be contextually appropriate $[1,8$, 9]. Modified to its social, cultural, spiritual and economic context, even resource constrained countries like Bhutan can provide effective PC services as demonstrated by Kerala in India, Arusha in Tanzania, Brasov in Romania, Vietnam and Argentina [1, 15, 80].

\section{Strengths and limitations}

There are several strengths and limitations to this study. Bhutan has varying cultural and belief systems in response to advanced illness, death and dying and postdeath rituals. A strength of this study was the inclusion of participants from all regions across the country. Although a sample size of 70 participants is small, the challenges faced to hear those 70 voices were great, and the study would be difficult to repeat for someone not fluent in the local dialects. The small sample size limited the inferential statistics to compare between cancer and non-cancer participants. One of the limitations was the use of only the EORTC-QLQ-30 which resulted in a reduced understanding of other needs such as information, spiritual and sexual needs of the patients. Due to complex practicalities including low literacy, issues with translation and the potential for encountering cultural taboos, we foresaw difficulties in using multiple tools and chose to use just one to maximise participation. This was also the first research conducted with this population in Bhutan. Future studies could consider a bigger sample and include other tools to explore additional needs in such patients.

\section{Conclusions}

The symptom burden experienced by people affected by advanced illnesses demonstrates the need for PC in Bhutan. Bhutan is a small developing nation with a small population and has primary health care and traditional healing systems underpinned by compassion and equity. With a very limited home PC service now initiated, this study of patients' needs will help inform the development of a broader public health-focused PC model, modified to the Bhutanese social, cultural and economic context, as recommended by the WHO.

\section{Abbreviations}

BHU: Basic Health Unit; EORTC QLQ-C30: European Organisation for Research and Treatment of Cancer Quality of Life Questionnaire; HIV: Human Immunodeficiency Virus; JDWNRH: Jigme Dorji Wangchuck National Referral Hospital; LMIC: Low and Middle Income Countries; PC: Palliative Care; QOL: Quality of Life; SAS: Statistical Analysis System; SD: Standard Deviation; WHO: World Health organization

\section{Acknowledgements}

We would like to thank our patient participants who participated despite knowing that there was no benefit to them but with faith that the research will make a difference to the future patients. We would also like to thank $\mathrm{Dr}$
Hanh Ngo, Research Fellow/ Biostatistician, MAPS PhD BSc (Hons), for her guidance with statistical analysis.

\section{Authors' contributions}

TDL collected the data, data analysis and prepared the manuscript. CJ conceived the idea. CS, CJ and KA reviewed and edited the manuscript. All authors read and approved the final manuscript.

\section{Funding}

TDL is supported by Australian Government International Research Training program Fees Offset Scholarship and Herta Massarik PhD Scholarship for Breast Cancer Research for 2018. These funding bodies were not involved in study design, collection, analysis, and interpretation of data or writing of the manuscript.

\section{Availability of data and materials}

The data that support the findings of this study are available on request from the corresponding author. The data are not publicly available due to privacy and ethical reasons.

\section{Ethics approval and consent to participate}

Ethical approval was provided by the Human Research Ethics Committee at the University of Western Australia and the Research Ethics Board of Health in Bhutan with Reference numbers, RA/4/20/4990 and REBH/Approval/2018/ 097, respectively. Informed consent was taken from every participant in the form of signature or thumb print.

\section{Consent for publication}

Not applicable.

\section{Competing interests}

The authors declare no competing interests.

\section{Author details}

${ }^{1}$ Medical School, The University of Western Australia, 35 Stirling Highway, 6009 Perth, Western Australia, Australia. ${ }^{2}$ Department of Nursing, Faculty of Nursing and Public Health, Khesar Gyalpo University of Medical Sciences of Bhutan, Thimphu, Bhutan. ${ }^{3}$ Medical School, Surgery Division, The University of Western Australia, 35 Stirling Highway, 6009 Perth, Western Australia, Australia. ${ }^{4}$ Rural Clinical School of Western Australia, The University of Western Australia, Science Building M701, 35 Stirling Terrace, 6330 Albany, Western Australia, Australia. ${ }^{5}$ Monash Nursing and Midwifery, Monash University, 10 Chancellors Walk, Wellington Road, 3800 Clayton, Victoria, Australia. ${ }^{6}$ Australian Health Services Research Institute (AHSRI), University of Wollongong, Building 234, Innovation Campus, 2522 Sydney, NSW, Australia.

Received: 25 August 2020 Accepted: 15 December 2020

Published online: 09 January 2021

\section{References}

1. Connor SR, Sepulveda-Bermedo MC, Global Atlas of Palliative Care at the End of Life. 2014: Worldwide Palliative Care Alliance, World Health Organization.

2. Gwyther L, Brennan F, Harding R. Advancing palliative care as a human right. J Pain Symptom Manage. 2009;38(5):767-74. DOl:https://doi.org/10. 1016/j.jpainsymman.2009.03.003.

3. Ezer T, Lohman D, de Luca GB. Palliative Care and Human Rights: A Decade of Evolution in Standards. J Pain Symptom Manage. 2018;55(2S):S163-9. https://doi.org/10.1016/j.jpainsymman.2017.03.027.

4. Brennan F. Palliative Care as an International Human Right. J Pain Symptom Manage. 2007;33(5):494-9. DOl:https://doi.org/10.1016/j.jpainsymman.2007. 02.022 .

5. World Health Organization. WHO Definition of Palliative Care. 2003 [cited 201826 March ]; Available from: http://www.who.int/cancer/palliative/ definition/en/

6. World Health Organization. Planning and implementing palliative care services: a guide for programme managers. 2016.

7. Swami M, Case AA. Effective palliative care: what Is involved? Oncology. 2018:32(4):180-4.

8. De Lima L, Radbruch L. The International Association for Hospice and Palliative Care: Advancing Hospice and Palliative Care Worldwide. J Pain 
Symptom Manage, 2018. 55(2S): p. S96-S103 DOl:https://doi.org/10.1016/j. jpainsymman.2017.03.023.

9. Connor SR, Gwyther E. The Worldwide Hospice Palliative Care Alliance. J Pain Symptom Manage. 2018;55(2S):112-6. DOl:https://doi.org/10.1016/j. jpainsymman.2017.03.020.

10. Knaul FM, et al., Alleviating the access abyss in palliative care and pain relief- an imperative of universal health coverage. Lancet Commission Report, 2017 DOI: https://doi.org/10.1016/S0140-6736(17)32513-8.

11. Clark D, Graham F, Centeno C. Changes in the world of palliative care. Medicine. 2015;43(12):696-8. DOl:https://doi.org/10.1016/..mpmed.2015.09.012.

12. Pastrana $\mathrm{T}$, et al. Disparities in the contribution of low-and middle-income countries to palliative care research. J Pain Symptom Manage. 2010;39(1): 54-68. DOl:https://doi.org/10.1016/j.jpainsymman.2009.05.023.

13. Sleeman $\mathrm{KE}$, et al. The escalating global burden of serious health-related suffering: projections to 2060 by world regions, age groups, and health conditions. Lancet Glob Health. 2019;7:e883-93. https://doi.org/10.1016/ S2214-109x(19)30172-X.

14. World Health Assembly. Strengthening of palliative care as a component of integrated treatment throughout the life course. 2014 [cited 201823 April]; Available from: http://apps.who.int/gb/ebwha/pdf_ files/WHA67/A67_31-en.pdf.

15. Clemens KE, et al. Palliative care in developing countries: what are the important issues? Editorial. Palliat Med. 2007;21(3):173-5. DOl.https://doi.org/ 10.1177/0269216307077460.

16. Hannon B, et al. Provision of Palliative Care in Low- and MiddleIncome Countries: Overcoming Obstacles for Effective Treatment Delivery. J Clin Oncol. 2016;34(1):62-8. DOl:https://doi.org/10.1200/jco. 2015.62.1615.

17. Stjernsward J. Palliative care: the public health strategy. J Public Health Policy. 2007;28(1):42-55. DOl:https://doi.org/10.1057/palgrave.jphp.3200115.

18. Callaway MV, Connor SR, Foley KM. World Health Organization Public Health Model: A Roadmap for Palliative Care Development. J Pain Symptom Manage. 2018;55(2S):6-13. DOl:https://doi.org/10.1016/j.jpainsymman.2017.03.030.

19. Stjernsward J, Foley KM, Ferris FD. The Public Health Strategy for Palliative Care. J Pain Symptom Manage. 2007;33(5):486-93. DOl:https://doi.org/10. 1016/j.jpainsymman.2007.02.016.

20. National Statistics Bureau, Statistical Yearbook of Bhutan 2019. 2019: Thimphu.

21. Dorii T, UN recommends Bhutan's LDC graduation, in Kuensel. 2018 March 19: Thimphu.

22. Thinley S, et al., The Kingdom of Bhutan Health System Review, in Asia Pacific Observatory on Health Systems and Policies, W. Patcharanarumol and V. Tangcharoensathien, Editors. 2017, World Health Organization: New Delhi, India.

23. Yangchen S, Tobgay T, Melgaard B. Bhutanese Health and the Health Care System: Past, Present, and Future. Druk J. 2016; 2(1).

24. MoH. Annual Health Bulletin. Thimphu: Ministry of Health; 2016

25. MoH. Annual Health Bulletin. Thimphu: Ministry of Health; 2018

26. Bay J, et al. Palliative Care: The Emerging Field in Bhutan. Clin J Oncol Nurs. 2019:23(1):108-11

27. Aaronson NK, et al. The European Organisation for Research and Treatment of Cancer QLQ-C30: A quality-of-life instrument for use in international clinical trials in oncology. J Natl Cancer Inst. 1993:85:365-76.

28. Rautalina $\mathrm{M}$, et al. Health-related quality of life in different states of breast cancer - comparing different instruments. Acta Oncol. 2018;57(5):622-8. DOl:https://doi.org/10.1080/0284186X.2017.1400683.

29. Thome B, Dykes AK, Hallberg IR. Quality of life in old people with and without cancer. Qual Life Res. 2004;13:1067-80.

30. SAS Institute Inc. 2002-2010 Cary, NC, USA.

31. BBC News. Cyclone Fani: Indians shelter from powerful storm. 2019 [cited 2020 April 23]; Available from: https:/www.bbc.com/news/world-asiaindia-48121606.

32. Lhamo P, Bus accident claims eight lives, in KUENSEL. 2019: Thimphu.

33. Wondie $Y$, Hinz A. Quality of life among Ethiopian cancer patients. Support Care Cancer. 2020. DOl:https://doi.org/10.1007/s00520-020-05398-w.

34. Herrera $\mathrm{E}$, et al. Regional palliative care program in Extremadura: an effective public health care model in a sparsely populated region. J Pain Symptom Manage. 2007;33(5):591-8. DOl:https://doi.org/10.1016/j. jpainsymman.2007.02.021.

35. Ndiok A, Ncama B. Assessment of palliative care needs of patients/families living with cancer in a developing country. Scand J Caring Sci. 2018;32(3): 1215-26. DOl:https://doi.org/10.1111/scs.12568.
36. Richardson A, et al. Patients' needs assessment in cancer care: a review of assessment tools. Support Care Cancer. 2007;15:1125-44. DOl:https://doi. org/10.1007/s00520-006-0205-8.

37. Rajagopal MR, Karim S, Booth CM. Oral Morphine Use in South India: A Population-Based Study. J Glob Oncol. 2017;3(6):720-7. DOl:https://doi.org/ 10.1200/jgo.2016.007872.

38. Fitch MI. Supportive care framework. CONJ. 2008;18(1):6-14. DOl:https://doi. org/10.5737/1181912x181614.

39. Combs AS, Davison SN. Palliative and end-of-life care issues in chronic kidney disease. Curr Opin Support Palliat Care. 2015;9(1):14-9. DOl:https:// doi.org/10.1097/SPC.0000000000000110.

40. Janssen DJ. Symptoms, comorbidities, and health care in advanced chronic obstructive pulmonary disease or chronic heart failure. J Palliat Med, 2011. 14 DOl:https://doi.org/10.1089/jpm.2010.0479.

41. Potosek J, et al. Integration of Palliative Care in End-Stage Liver Disease and Liver Transplantation. J Palliative Med. 2014;17(11):1271-7. https://doi.org/10. 1089/jpm.2013.0167.

42. Daya AP, Sarkar S, Kar SS. Needs of People Requiring Palliative Care in an Urban Area of Pondicherry, South India: An Exploratory Study National J Community Med, 2018. 9(5).

43. Bates MJ, Mijoya A. A review of patients with advanced cervical cancer presenting to palliative care services at Queen Elizabeth Central Hospital in Blantyre, Malawi. Malawi Med J. 2015;27(3):93-5. https:/doi.org/10.4314/mmj.v27i3.4.

44. Lewington J, et al. Provision of palliative care for life-limiting disease in a low income country national hospital setting: how much is needed? BMJ Supportive Palliative Care. 2012;2(2):140-4. DOl:https://doi.org/10.1136/ bmjspcare-2011-000188.

45. Perone SA, et al. Addressing the needs of terminally-ill patients in BosniaHerzegovina: patients' perceptions and expectations. BMC Palliative Care. 2018:17(1):123. DOl:https://doi.org/10.1186/s12904-018-0377-2.

46. Yun $\mathrm{YH}$, et al. Age, sex, and comorbidities were considered in comparing reference data for health-related quality of life in the general and cancer populations. J Clin Epidemiol. 2007;60:1164-75. https://doi.org/10.1016/j. jclinepi.2006.12.014.

47. Nolte S, et al, General population normative data for the EORTC QLQ-C30 health-related quality of life questionnaire based on 15,386 persons across 13 European countries, Canada and the Unites States. Eur J Cancer 107 (2019) 153e163, 2019. 107: p. 153-163 DOl: https://doi.org/10.1016/.ejca.2018.11.024.

48. Mercieca-Bebber R, et al. The EORTC Quality of Life Questionnaire for cancer patients (QLQ-C30): Australian general population reference values. MJA. 2019;210(11):499-506. DOl:https://doi.org/10.5694/mja2.50207.

49. Finck $C$, et al. Health-related quality of life in Colombia: reference values of the EORTC QLQ-C30. Eur J Cancer Care. 2012;21:829-36. https://doi.org/10. 1111/ecc.12000.

50. Coughlan M. Pain and Palliative Care for People Living with HIV/AIDS in Asia. J Pain Palliative Care Pharmacotherapy. 2009;17(3-4):91-104. https:// doi.org/10.1080/J354v17n03 13.

51. Cherny NI, Coyle N, Foley KM. Suffering in the advanced cancer patient: a definition and taxonomy. J Palliat Care. 1994;10(2):57-70. DOl:https://doi. org/10.1177/082585979401000211.

52. Ministry of Health. National Essential Medicines List 2018. 2018 [cited 2020 June 4]; Available from: http://www.moh.gov.bt/national-essentialmedicines-list-2018/.

53. Bennett DS, Carr DB. Opiophobia as a Barrier to the Treatment of Pain. Journal of Pain Palliative Care Pharmacotherapy. 2009;16(1):105-9. DOI: https://doi.org/10.1080/J354v16n01_09.

54. Dehghan $\mathrm{R}$, et al. The use of morphine to control pain in advanced cancer: an investigation of clinical usage in Bangladesh. Palliat Med. 2010;24(7):70714. DOl:https://doi.org/10.1177/0269216310376260.

55. Bhatnagar S, Joshi S. Palliative Care of Young Adults: An Issue which Needs Higher and Better Awareness. Indian J Palliat Care. 2011;17(3):173-4.

56. Aoun SM, et al., Bereavement support for family caregivers: the gap between guidelines and practice in palliative care. PLoS One, 2017. 12: e0184750 DOl: https://doi.org/10.1371/journal.pone.0184750.

57. Griese B, et al. Comprehensive Grief Care for Children and Families: Policy and Practice Implications. American Journal of Orthops. 2017:87(5):540-8. DOl:https://doi.org/10.1037/ort0000265.

58. Morrison RS. A national palliative care strategy for Canada. J Palliat Med. 2018;21:S-63-75. DOl:https://doi.org/10.1089/jpm.2017.0431.

59. DeWalt DA, et al. Literacy and Health Outcomes: A Systematic Review of the Literature. JGIM. 2004;14:1228-39. 
60. Shahid S, et al. Key features of palliative care service delivery to Indigenous peoples in Australia, New Zealand, Canada and the United States: a comprehensive review. BMC Palliat Care. 2018;17(1):72. DOl:https://doi.org/ 10.1186/s12904-018-0325-1.

61. Hostad J, MacManus D, Foyle L, Public Information and Education in Palliative Care. Delivering Cancer and Palliative Care Education, ed. L. Foyle and J. Hostad. 2004, 6000 Broken Sound Parkway, NW, Suite 300: CRC Press, Taylor \& Francis Group.

62. Ministry of Health. National Health Policy. 2015 [cited 20184 June]; Available from: http://www.health.gov.bt/wp-content/uploads/moh-files/2015/11/ National-Health-Policy.pdf.

63. Khan Rl. Palliative care in Pakistan. Indian J Med Ethics. 2017;2(1):37-42. DOI: https://doi.org/10.20529/ijme.2017.007.

64. Lal M, et al. Palliative Care Tailored Towards the Needs of the Poor in India. Indian J Surg Oncol. 2015;6(3):227-31. DOl:https://doi.org/10.1007/s13193015-0409-9.

65. Bhutan Cultural Atlas. Traditional Healing and Practices in Bhutan. 2017 [cited 20187 June]; Available from: https://www.bhutanculturalatlas.org/166/ culture/intangible-heritage/traditional-healing-practices/traditional-healingand-practices/.

66. Wangchuk P, Wangchuk D, Aagaard-Hansen J. Traditional Bhutanese Medicine (gSo-BA Rig-PA): an integrated part of the formal health care services. Southeast Asian J Tropical Med Public Health. 2007;38(1):161-7.

67. Campbell L, Amin N, A qualitative study: potential benefits and challenges of traditional healers in providing aspects of palliative care in rural South Africa. Rural Remote Health, 2014. 14(2).

68. Sharan M, Mazanah M. Roles traditional healers play in cancer treatment in Malaysia: implications for health promotion and education. Asian Pac J Cancer Prev. 2013;14(6):3593-601.

69. Ben-Arye E, et al., Integrating Complementary and Traditional Practices in Middle-Eastern Supportive Cancer Care. J Natl Cancer Inst Monogr, 2017. 2017(52) DOl:https://doi.org/10.1093/jncimonographs/lgx016.

70. Barnas $\mathrm{E}$, et al. The quality of life of women treated for cervical cancer. Eur J Oncol Nurs. 2012;16:59-63. https://doi.org/10.1016/j.ejon.2011.03.001.

71. Kato J, et al. Evaluation of EORTC QLQ-C30 questionnaire in patients undergoing in-hospital chemotherapy for gastrointestinal cancer in Japan. J Gastroenterol Hepatol. 2008;23(2):S268-72. DOl:https://doi.org/10.1111/j. 1440-1746.2008.05414.x.

72. Murray SA, et al., Dying from cancer in developed and developing countries: lessons from two qualitative interview studies of patients and their carers. BMJ, 2003. 326(7385.368).

73. Murtagh FEM, et al. How many people need palliative care? A study developing and comparing methods for population-based estimates. Palliat Med. 2014;28(1):49-58. DOl:https://doi.org/10.1177/0269216313489367.

74. Herce ME, et al. Assessing and responding to palliative care needs in rural sub-Saharan Africa: results from a model intervention and situation analysis in Malawi. PLoS One. 2014;9(10):e110457. DOl:https://doi.org/10.1371/ journal.pone.0110457.

75. Gwyther L, Heap M, London L. Access to palliative care in HIV services in Cape Town. AIDS Care. 2018;30(sup2):11-5. DOl:https://doi.org/10.1080/ 09540121.2018 .1470307$.

76. Bakitas $\mathrm{M}$, et al. Oncologists' perspectives on concurrent palliative care in a National Cancer Institute-designated comprehensive cancer center. Palliative Supportive Care. 2012;11:415-23. DOl:https://doi.org/10.1017/ S1478951512000673.

77. Palma RD, et al. Effectiveness of palliative care services: A population-based study of end-of-life care for cancer patients. SAGE Journal Palliative Medicine. 2018. DOl:https://doi.org/10.1177/0269216318778729.

78. World Health Assembly. Strengthening of palliative care as a component of integrated treatment throughout the life course: Report by the Secretariat. 2014

79. Leng A, et al., Geographical disparities in treatment and health care costs for end-of-life cancer patients in China: a retrospective study. BMC Cancer, 2019. 19(39) DOl:https://doi.org/10.1186/s12885-018-5237-1.

80. Bollini P, Venkateswaran C, Sureshkumar K. Palliative care in Kerala, India: a model for resource-poor settings. Onkologie. 2004;27(2):138-42. DOl:https:// doi.org/10.1159/000076902

\section{Publisher's Note}

Springer Nature remains neutral with regard to jurisdictional claims in published maps and institutional affiliations.

\section{Ready to submit your research? Choose BMC and benefit from}

- fast, convenient online submission

- thorough peer review by experienced researchers in your field

- rapid publication on acceptance

- support for research data, including large and complex data types

- gold Open Access which fosters wider collaboration and increased citations

- maximum visibility for your research: over $100 \mathrm{M}$ website views per year

At BMC, research is always in progress.

Learn more biomedcentral.com/submissions 